\title{
Awareness, Attitude and Practices Regarding Breast Cancer Screening among Community Women
}

\author{
Ratna Kumari Maharjan ${ }^{1}$, Bimala Panthee ${ }^{1}$, Shanti Awale ${ }^{2}$ \\ ${ }^{1}$ Assistant Professor, Patan Academy of Health Sciences, School of Nursing and Midwifery, Sanepa, Lalitpur, \\ Nepal \\ ${ }^{2}$ Associate Professor, Patan Academy of Health Sciences, School of Nursing and Midwifery, Sanepa, Lalitpur, \\ Nepal
}

Corresponding Author: Ratna Kumari Maharjan ratnamaharjan@pahs.edu.np

\begin{abstract}
Background: Breast cancer is the most common cancer among women worldwide. In Nepal, it is the second most common cancer. Early detection of breast cancer serves a leading role in the reduction of breast cancer mortality. The aim of this study was to assess the awareness, attitude and practices regarding breast cancer screening among community women

Method: A cross sectional descriptive study was carried among 316 community women. Probability simple random sampling technique was used to select the sample. Self-administered questionnaire was used to collect data. Data analysis was done by using SPSS version 16.

Result: Our results indicated that very few (7.3\%) participants had good knowledge towards breast cancer screening. Half (50\%) had poor attitude. Sixty two percent of participants had done breast selfexamination, one fourth (25\%) had done clinical breast examination and very low (10\%) had done mammogram. Though very few participants demonstrated good knowledge, about $90 \%$ of participants were aware that lump in breast can be related to breast cancer and agreed that every woman is risk for breast cancer.

Conclusion: Majority of women demonstrated poor knowledge, attitude and practice towards breast cancer screening. Thus, effort should be put forth to increase the awareness of breast cancer screening for the early detection of breast cancer in the early stage.
\end{abstract}

Key Words: attitude, awareness, practice, breast cancer screening, community women

\section{INTRODUCTION}

The predicted global burdens of cancer will double to about 29-37 million new cancer cases by $2040^{1}$. Breast cancer is the most common cancer among women worldwide. In 2020, 2,261,419 million new cases of breast cancer were diagnosed globally accounting for $24.5 \%$ of all cancer $^{2}$. Cancer is the fifth leading cause of death in $\mathrm{Nepal}^{3}$, where breast cancer is one of the most common causes of death among women being the second most common cancer after cervical cancer ${ }^{4}$. However, there is lack of national breast cancer program in Nepal, while at local level is necessary to raise awareness of the symptoms and their attitudes towards treatment $^{5}$. Due to the unavailability of a population-based cancer registry it is difficult to precisely predict of future incidence rates. Considering this fact, Nepal government has started to generate evidence on the incidence on various types of cancer patterns and trends of disease and mortality related to cancer since $2018^{3}$.

Early diagnosis is the best alternative for many cancers. For the early detection and diagnosis of breast cancer, awareness of early signs of cancer among women is vital. Currently, in most low and middle- income countries, cancer is diagnosed at an advanced stage, when 
treatment is generally less effective, more expensive and more disabling ${ }^{1}$. Previous studies on breast cancer have shown that breast cancer screening programs for early diagnosis and early treatment can increase the survival ${ }^{6}$. Clinical Breast examination (CBE), breast self- examination (BSE), and mammography for breast cancer screening (BCS) are simple method but have important roles in early diagnosis. American cancer society has recommended that women ages 40 to 44 should have the choice to start annual breast cancer screening with mammograms and women age 44 to 54 should get mammograms every year. Similarly, women 55 and older should do mammograms every 2 years or can continue yearly screening. Also, all women should be familiar with the known benefits, limitation, and potential harms linked to breast cancer screening. In addition, women should also know how their breast normally look and feel and report breast changes to a health care provider right away ${ }^{7}$. Practice of BSE is also beneficial for the early detection of cancer and the incidence rate was low among those who were instructed for BSE after 11 years tough non-significant. However, mortality rate was not much difference $^{6}$. Thus, our focus should be on preventive aspect of breast cancer.

However, practices of breast cancer screening depend on the awareness level and attitude of women. In a study conducted among 1353 Jordanian women 44\% and $55 \%$ of participants had knowledge regarding sign and symptoms of breast cancer and its risk factors, respectively ${ }^{8}$. On the other hand, $70 \%-80 \%$ of cancer cases in Kenya were screened at later stages due to a lack of awareness, inadequate diagnostic facilities, lack of treatment facilities, high cost of treatment and high poverty index ${ }^{9}$. Similarly, in Iran, $52 \%$ of participants had low knowledge on breast cancer risk factors ${ }^{10}$. In India, 91\% of participants were not aware about the risk factors of breast cancer, $90 \%$ were not aware about the symptoms of breast cancer and 93\% were not aware about the preventive measures of breast cancer. None of them were aware of BSE as an important early detection measure for breast cancer ${ }^{11}$. In addition, it has been found that most of the respondents had heard of breast cancer but $60 \%$ of them thought that it affects only elderly women. Only $16 \%$ were aware of BSE but very few practiced it ${ }^{12}$, though, breast cancer is more common among younger and premenopausal women ${ }^{13}$.

In a study conducted in Nepal among 1420 female, demonstrated poor awareness of warning signs and screening methods. In addition, the practice of mammography was only $20 \%{ }^{14}$. Among different methods of screening for breast cancer, BSE, CBE and mammography are the most effective steps highlighting that cancer screening is regarded as the optimal method for early detection and prompt management ${ }^{15}$. Because of the less awareness and poor attitude and practice of breast cancer screening methods late diagnosed at an advanced stage is more common in Nepal which eventually shows poor prognosis ${ }^{13}$. Thus, this study aims to assess awareness, attitude and practice of breast cancer screening among urban community women.

\section{METERIALS AND METHODS}

A descriptive cross-sectional research design was used to conduct a research among 316 women at Lalitpur Metropolitan Lalitpur, Nepal. Community women in this study were mother groups of ward number 8 who are committed to selfempowerment including social and financial growth. In Lalitpur District, there are total 29 wards. Due to COVID-19 pandemic, we chose ward no 8 conveniently. This ward is situated in 5 kilometers south from international airport, Kathmandu. There are ten mother groups in this ward (Table 1). Data was collected from June to July, 2021. 
Ratna Kumari Maharjan et.al. Awareness, attitude and practices regarding breast cancer screening among community women.

Table 1. Name of mothers' group, number of members in each and sample taken from each mother's group

\begin{tabular}{|l|l|l|l|}
\hline S N & Name of mother's group & No. of members in the group & Sample taken for the study (using proportion ratio) \\
\hline 1 & Guita Maa pucha & 115 & 45 \\
\hline 2 & Subahal Maa pucha & 115 & 45 \\
\hline 3 & Jay manohar misha pucha,subahal & 30 & 12 \\
\hline 4 & Saraswoti Maa pucha, sako & 90 & 34 \\
\hline 5 & Pinchhen Maa pucha,pinchhen & 192 & 76 \\
\hline 6 & Chapat mahila samuh,Chapat & 40 & 16 \\
\hline 7 & Yalamul misha pucha,yalamul & 80 & 32 \\
\hline 8 & Bal Kumari Maa Amma samuh,Balkumari & 62 & 24 \\
\hline 9 & Jagruk mahila samuh,kutisaugal & 35 & 14 \\
\hline 10 & Jana hit Mahila samuh,yangu bahal & 45 & 18 \\
\hline Total & $\mathbf{8 0 4}$ & $\mathbf{3 1 6}$ \\
\hline
\end{tabular}

Sampling technique: Probability sampling method using simple random sampling technique (lottery) was used to select the sample.

\section{Sample size and sample size calculation:}

Sample size $(\mathrm{n})=\frac{z 2 p q}{e 2}$

Where,

$\mathrm{n}=$ required sample size

$\mathrm{z}=$ confidence level at $95 \%$

$\mathrm{p}=$ estimated predicted or anticipated rate for a given indicator in the study area $29 \%^{9}$ Rosemary

$\mathrm{q}=1-\mathrm{p}$

$\mathrm{e}=$ margin of error at $5 \%($ standard value of 0.05)

Sample size $(\mathrm{n})=\frac{1.96^{2} \times 0.29 \times(1-0.29)}{0.05^{2}}$

Total sample size $=316$

Thus, total calculated sample size was 316

\section{Inclusion and exclusion criteria:}

Women of 20 to 60 years of age who were involved in mothers' group of ward number 8 Lalitpur, and those who could read and write were included in the study. Those women who had history of breast cancer or breast tumor, who had any previous breast surgeries and who were health worker were excluded from the study.

\section{Working definition:}

Awareness of breast cancer screening was considered as the understanding of women involved in mothers' group about, early sign and symptoms of breast cancer, risk factors of breast cancer and methods of screening.
Attitude of breast cancer screening in this study was the way of thinking and behaving of community women regarding breast cancer screening.

Practice of breast cancer screening was considered as the activities done by the women to detect early signs of breast cancer like breast self-examination, clinical breast examination, and mammography.

\section{Instruments to measure variables}

Socio-demographic information: age (in years), education (read and write, primary, secondary, and above secondary), marital status (married, unmarried, widow/widowed), and number of children.

Awareness related questionnaire: It is a selfdeveloped questionnaire which consists of total 9 questions. The response options were multiple choice (3 items), "Yes" or" No" (3 items), and multiple response (3 items). Total score ranges from 0-22. The awareness level was categorized as "poor knowledge" $<50 \%$, "fair knowledge" 50$75 \%$ and "good knowledge" $>75 \%{ }^{16}$.

Attitude related questionnaire: It is a selfdeveloped 10 items questionnaire with 3point Likert scale where participants showed their agreement (1=disagree, $2=$ neutral, $3=$ agree) in each statement. Six items were positively phrased and 4 items were negatively phrased. Total score ranges from 10-30. The attitude was categorized as good attitude and poor attitude. To categorize the attitude level median value was taken as reference ${ }^{17}$.

Practice related questionnaire: It is a selfdeveloped six items questionnaire where respondents were asked if they have been 
doing Self breast examination (SBE), Clinical breast examination (CBE) and Mammography in yes or no option. If they had done any practice, they were further asked at what age they started doing that examination.

All the questionnaires were developed based on previous literatures. Content validity and face validity was assured with content experts.

\section{Data collection procedure:}

Data was collected utilizing lottery method with replacement. Self-administered questionnaire was distributed to the respondents. Every month of first and second calendar day, the women of these mothers' group conduct a meeting for regular cash collection. After the completion of their meeting, those women who were selected for the sample of the study, were requested to fill up the questionnaire. All the members came to the meeting either in first or second day. Thus, data collection was done in those two days from each group.

\section{Data analysis procedure:}

Data was analyzed using SPSS version 16. Descriptive statistics (frequency, percentage, mean and standard deviation) was used to analyze the data and presented in the tables. Chi-square test and Pearson correlation analysis was used to examine the association and relationship between variables, respectively. Regarding knowledge categorization fair knowledge was merged to good knowledge. For analysis of awareness, " 1 " score was given for right answer and " 0 " was given for the incorrect answer. For analysis of the attitude, the negatively phrased statements were re-coded during analysis. Thus, total score ranges from 10-30. For analysis of practice, 1 score was given if they responded yes and 0 was given if they responded no.

\section{Ethical consideration:}

Data was collected after ethical approval from Institutional Review Committee, PAHS (nrs 210615138). Participants' information sheet was distributed with the questionnaire. After reading the information sheet, if respondents agree to participate in the study, selfadministered questionnaire was distributed. Respondents had the right to decide to not to participate in the study in between if they wish. The return of filled questionnaire was considered the voluntarily participation in the study. Respondents were not required to write any identification code or name in the questionnaire to maintain their privacy of the information.

\section{RESULTS}

\section{Socio demographic characteristics}

A total of 316 questionnaires were analyzed for the study. Mean age (SD) of participants was 44.39 (7.16) years where about $50 \%$ of participants were in between 40 and 49 years of age. All participants were married and only 5 participants did not have children. About $40 \%$ could only read and write (Table 2).

Table 2. Socio-demographic characteristics of participants, $\mathbf{N}=316$

\begin{tabular}{|l|l|l|}
\hline Characteristics & Frequency & Percentage \\
\hline Age (In years) & 4 & \\
20-29 & 78 & 1.3 \\
$30-39$ & 151 & 24.7 \\
$40-49$ & 83 & 47.8 \\
50 and above50 & & 26.2 \\
Mean age 44.39 \pm 7.162 & 115 & 36.4 \\
\hline $\begin{array}{l}\text { Education } \\
\text { Read and write } \\
\text { Primary education (class 1 to 5 } \\
\text { class) }\end{array}$ & 38 & 12.0 \\
Secondary education (class 6to & 118 & 37.4 \\
$\begin{array}{l}\text { 12 class) } \\
\text { Above secondary education } \\
\text { (above 12 class) }\end{array}$ & 45 & 14.2 \\
\hline $\begin{array}{c}\text { Marital status } \\
\text { Married }\end{array}$ & & \\
Widow & 312 & 98.7 \\
\hline If married, do you have children? & 4 & 1.3 \\
$\quad \begin{array}{l}\text { Yes } \\
\text { No }\end{array}$ & 311 & 98.1 \\
\hline
\end{tabular}

\section{Participants' knowledge about breast} cancer and breast cancer screening

Regarding the knowledge on breast cancer screening nearly half of the respondents $(48.1 \%)$ had poor knowledge 
and only few (7.3\%) had good knowledge (Table 3). We further analyzed each item of knowledge questionnaire. Only correct response has been mentioned in the table. Regarding meaning of breast cancer in terms of "lump and changes in breast shape" $90 \%$ participants answered correctly. Likewise in the question "breast cancer is a hereditary disease" only $33.5 \%$ participants answered correctly. Regarding risk factors, about $50 \%$ participants answered correctly for positive family history and only $17 \%$ were aware that women who have first child after 30 years are on risk of developing breast cancer. Similarly, $90 \%$ of participants were aware that lump in breast is a sign of breast cancer and 33\% answered correctly that discoloration/dimpling of breast is a sign of breast cancer. Regarding diagnosis, $72 \%$ of participants reported that clinical examination by doctor is the diagnostic measure of breast cancer and few 28\% reported that ultrasonography can detect breast cancer. (Table 4).

Table 3. Overall Level of knowledge on breast cancer screening among respondents, $\mathrm{N}=316$

\begin{tabular}{|l|l|l|}
\hline Level of knowledge & Frequency & Percentage \\
\hline Poor knowledge $<50 \%$ & 152 & 48.1 \\
\hline Fair Knowledge $50-75 \%$ & 141 & 44.6 \\
\hline Good knowledge $>75 \%$ & 23 & 7.3 \\
\hline
\end{tabular}

Table 4. Participants' knowledge on breast cancer screening questions, $N=316$

Table 4. Participants' knowledge on breast cancer screening questions, N= 316
\begin{tabular}{|l|l|l|}
\hline Questions & Frequency & Percentage \\
\hline If there is breast lump and changes in breast shape it might be breast cancer & 288 & 91.1 \\
\hline Breast cancer is hereditary disease & 106 & 33.5 \\
\hline Risk factor & & \\
\hline Obesity & 96 & 30.4 \\
\hline Tobacco use & 142 & 44.9 \\
\hline Positive family history & 150 & 47.5 \\
\hline Unmarried or infertile women & 94 & 29.7 \\
\hline First child after 30 years & 54 & 17.1 \\
\hline Early menarche before 12 years & 67 & 21.2 \\
\hline Late menopause after 55 years & 68 & 21.5 \\
\hline Sign and symptoms & & \\
\hline Discharge from nipple & 121 & 38.3 \\
\hline Lump in breast & 286 & 90.5 \\
\hline Pain and soreness in breast & 144 & 45.6 \\
\hline Changes in shape and size of breast and nipple & 118 & 37.3 \\
\hline Discoloration/dimpling of breast & 105 & 33.2 \\
\hline Diagnosis & & \\
\hline Self-breast examination & 190 & 60.1 \\
\hline Clinical examination by doctor & 226 & 71.5 \\
\hline Mammography & 189 & 59.8 \\
\hline Ultrasonography & 89 & 28.2 \\
\hline
\end{tabular}

\section{Participants' attitude towards breast cancer screening}

Overall, about half $(50.9 \%)$ participants had good attitude towards breast cancer screening (Table 5) and 84\% participants agreed that any woman is at risk of breast cancer and 93\% agreed that breast cancer can be prevented. However, half of the participants agreed that if there is no problems in breast, periodic breast examination is not required (Table 6).

Table 5. Overall Attitude level on Breast Cancer screening among respondents $=316$

\begin{tabular}{|l|l|l|}
\hline Level of Attitude & Frequency & Percentage \\
\hline Good attitude & 161 & 50.9 \\
\hline Poor Attitude & 155 & 49.1 \\
\hline
\end{tabular}

Association between demographic variables with knowledge and attitude of women towards breast cancer screening

It has been found that age category showed significant different in knowledge level meaning that higher percentage $(56 \%)$ women aged above 40 years showed good knowledge however, only $42 \%$ women aged below 40 years showed good knowledge on breast cancer screening. None of the other variables were not significantly associated with knowledge and attitude level (Table 7). We found a significant positive correlation $(r=.14, \mathrm{p}=.01)$ between knowledge and attitude. 
Ratna Kumari Maharjan et.al. Awareness, attitude and practices regarding breast cancer screening among community women.

Table 6. Participants' response on attitude related questions, $\mathrm{N}=316$

\begin{tabular}{|l|l|l|l|l|}
\hline S.N & Statements & Agree & Neutral & Disagree \\
\hline 1 & Any woman is risk for breast cancer & $265(83.9)$ & $19(6)$ & $32(10.1)$ \\
\hline 2 & Breast cancer is curable when detected early & $294(93)$ & $18(5.7)$ & $4(1.3)$ \\
\hline 3 & Breast self-examination is useful for early detection of breast cancer & $254(80.4)$ & $38(12.0)$ & $24(7.6)$ \\
\hline 4 & Breast self-examination is painful procedure* & $81(25.6)$ & $87(27.5)$ & $148(46.8)$ \\
\hline 5 & Being fear of detecting breast cancer, I would not perform BSE* & $63(19.9)$ & $73(23.1)$ & $180(57.0)$ \\
\hline 6 & If there is no problem in breast, periodic breast examination is not required & $141(44.6)$ & $48(15.2)$ & $127(40.2)$ \\
\hline 7 & Breast self-examination should be done monthly & $260(82.3)$ & $35(11.1)$ & $21(6.6)$ \\
\hline 8 & By early diagnosis of breast cancer, the person will have prolonged life & $276(87.3)$ & $30(9.5)$ & $10(3.2)$ \\
\hline 9 & Clinical breast examination should be performed by female doctors only* & $79(25.0)$ & $43(13.6)$ & $194(61.4)$ \\
\hline 10 & Mammography is only method towards screening breast cancer* & $193(61.1)$ & $64(20.3)$ & $59(18.7)$ \\
\hline
\end{tabular}

Note: parentheses are percentage, * negatively phrased statement

Table 7. Association of demographic variables with knowledge and attitude of women towards breast cancer screening, $\mathrm{N}=316$

\begin{tabular}{|c|c|c|c|c|c|c|c|c|}
\hline \multirow[t]{2}{*}{ Variables } & \multicolumn{2}{|c|}{ 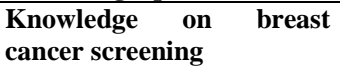 } & \multirow{2}{*}{$\begin{array}{l}\text { Chi } \\
\text { square } \\
\text { value }\end{array}$} & \multirow[t]{2}{*}{$\begin{array}{l}P \\
\text { value }\end{array}$} & \multicolumn{2}{|c|}{$\begin{array}{l}\text { Attitude on breast cancer } \\
\text { screening }\end{array}$} & \multirow[t]{2}{*}{$\begin{array}{l}\text { Chi square } \\
\text { value }\end{array}$} & \multirow[t]{2}{*}{$\begin{array}{l}P \\
\text { value }\end{array}$} \\
\hline & Good & Poor & & & Good & Poor & & \\
\hline $\begin{array}{c}\text { Age (in years) } \\
\text { Below } 40 \\
\text { Above } 40\end{array}$ & $\begin{array}{l}34(41.5) \\
130(55.6)\end{array}$ & $\begin{array}{l}48(58.5) \\
104(44.4)\end{array}$ & 4.83 & .02 & $\begin{array}{l}45(54.9) \\
116(49.6)\end{array}$ & $\begin{array}{l}37(45.1) \\
118(50.4)\end{array}$ & .68 & .40 \\
\hline $\begin{array}{l}\text { Education } \\
\text { Up to primary } \\
\text { Above primary }\end{array}$ & $\begin{array}{l}82(53.6) \\
82(50.3)\end{array}$ & $\begin{array}{l}71(46.4) \\
81(49.7)\end{array}$ & .34 & .55 & $\begin{array}{l}71(46.4) \\
90(55.2)\end{array}$ & $\begin{array}{l}82(53.6) \\
73(44.8)\end{array}$ & 2.45 & .11 \\
\hline
\end{tabular}

\section{Participants' practice on breast cancer screening}

Regarding practice towards breast screening, $62.0 \%$ of respondents had done breast self-examination (BSE) and half of them had started doing BSE since the age of 50 . And one fourth $(25 \%)$ had done clinical breast examination (CBE). However, only $10 \%$ participants had done mammogram (Table 8).

Table 8. Practices on breast cancer screening among respondents: $\mathrm{N}=316$

\begin{tabular}{|c|c|c|}
\hline $\begin{array}{l}\text { Practices on } \\
\text { examination }\end{array}$ & Frequency & Percentage \\
\hline \multicolumn{3}{|l|}{$\begin{array}{l}\text { Have you ever done breast self- } \\
\text { examination? }\end{array}$} \\
\hline Yes & 196 & 62.0 \\
\hline No & 120 & 38.0 \\
\hline \multicolumn{3}{|l|}{ If yes, initial age of BSE ( $n=196)$} \\
\hline From 20 years & 33 & 16.3 \\
\hline From 30 years & 99 & 49.0 \\
\hline From 40 years & 60 & 29.7 \\
\hline From 50 years & 10 & 5.0 \\
\hline \multicolumn{3}{|l|}{$\begin{array}{lll}\text { Practices on clinical } & \text { breast } \\
\text { examination }(\mathrm{CBE}) & \\
\end{array}$} \\
\hline \multicolumn{3}{|l|}{$\begin{array}{l}\text { Have you ever had breast } \\
\text { examination by Doctor? }\end{array}$} \\
\hline Yes & 78 & 24.4 \\
\hline No & 238 & 75.6 \\
\hline $\begin{array}{l}\text { If yes, time of doing clinical breast } \\
\text { examination }(n=78)\end{array}$ & & \\
\hline During menstruation & 2 & 2.6 \\
\hline $\begin{array}{l}\text { Between the } 7-10 \text { days after } \\
\text { menstruation }\end{array}$ & 31 & 39.7 \\
\hline After 14 days of menstruation & 21 & 26.9 \\
\hline Any time during menstruation & 24 & 30.8 \\
\hline \multicolumn{3}{|l|}{ Practices on mammography } \\
\hline $\begin{array}{l}\text { Have you done mammography? } \\
\text { Yes } \\
\text { No }\end{array}$ & $\begin{array}{l}29 \\
287\end{array}$ & $\begin{array}{l}9.2 \\
90.8\end{array}$ \\
\hline
\end{tabular}

\section{DISCUSSION}

Knowledge and awareness play a vital role in early detection and optimal treatment of breast cancer and motivates for practicing breast cancer screening. The knowledge level of community women and their attitudes towards screening methods for breast cancer are important determinants of the practice of these methods. Thus, we conducted to assess the knowledge, attitudes, and practices of breast cancer screening in community women. Regarding knowledge, this study focused on breast cancer, risk factors of breast cancer, sign and symptoms of breast cancer and diagnosis. Attitude related to breast cancer and its screening was assessed. And practice was asked if each woman has done breast cancer screening. Breast cancer screening practice in this study was BSE, CBE and mammogram. Good knowledge towards breast cancer screening in this study's participants was very low which was only $7 \%$ and $50 \%$ had poor knowledge. Higher level of awareness towards any changes in breasts contributes to early diagnosis of breast cancer. On the other hand, poor level of understanding of risk factors and screening methods may lead to women rarely or never checking their breasts ${ }^{18}$. Additionally, early diagnosis of breast cancer is known to reduce breast cancer 
mortality ${ }^{6}$. The low level of knowledge towards breast cancer screening in this study is similar to other studies in Indonesia, Saudi Arabia, Iran ${ }^{18,19,16}$. In addition, in the study conducted in Indonesia, it was found that women from urban area had low level of knowledge than the women from rural $\operatorname{area}^{18}$. The population of this study was also from the urban areas (capital city of Nepal) who were indigenous Newar community women. Though, $50 \%$ of women had poor knowledge, $91 \%$ had knowledge that lump and change in breast might be breast cancer. But many of them were unaware that it is hereditary disease. Moreover, participants in this study were unaware on risk factors. Regarding sign and symptoms, most of women were unaware except lump in breast and pain in breast. More women, aged above 40 years, had good knowledge towards breast cancer screening than the women aged below 40 years.

Half of the participants had good attitude towards breast cancer screening. In most of the statement positively phrased statement, more than $80 \%$ of participants agreed. For instance, any woman is risk of breast cancer, breast cancer is curable when detected early, BSE should be done monthly, and early diagnosis can prolong the life. However, in the statement "being fear of detecting breast cancer I would not perform BSE" $45 \%$ of participants agreed or neutral which is discouraging. Similarly, statement "breast self-examination is painful procedure" about half (53\%) of participants either agreed or neutral on it. Significant positive association between knowledge and attitude reflects that those who have higher knowledge towards breast cancer screening will have good attitude towards breast cancer screening thereby will facilitate for the practice of it. However, age and education level did not show significant association between attitude level.

With regard to practice, the results of this study were not satisfactory except for BSE. The awareness level of BSE and practice of BSE was similar (about 90\%). This is much higher than the rate of BSE found in some other studies ${ }^{19}$ where only $35 \%$ of participants were performed breast self-examination/ though CBE and mammogram was not satisfactory and very few participants were practicing, the higher number of participants practicing BSE is very encouraging. When comparing the overall breast cancer screening practice to the study conducted in Ethiopia $(6.9 \%)^{20}$, the BCS practice is higher in this population though not satisfactory. Regarding BSE the findings of this study are comparable to the findings conducted in Saudi Arabia ${ }^{16}$ among healthcare professionals. As study area was the urban city and different breast cancer screening program might have been conducted in this area. However, in a study conducted in western region of Nepal, only $10.9 \%$ participants were practicing $\mathrm{BSE}^{21}$.

\section{CONCLUSION}

Based on the findings of this study it can be concluded that knowledge towards breast cancer screening of community women is low and half of them had poor attitude towards breast cancer screening. However, breast self-examination practice was satisfactory but other screening practices were very low. Significant positive relationship between knowledge and attitude suggests that there is a need for awareness related program towards breast cancer screening for early detection and prevention of breast cancer among the women.

\section{ACKNOWLEDGEMENT}

We acknowledge all the members of the mother's group who voluntarily participate in this study.

\section{Conflict Of Interest}

We declare that we do not have any conflict of interest.

\section{Source of Funding: None}

Ethical Approval: Approved 


\section{REFERENCES}

1. World Health Organization. WHO report on cancer: setting priorities, investing wisely and providing care for all. ISBN 978-92-4000129-9 World Health Organization 2020 [web link] [Google Scholar][Full Text]

2. Ferlay J, Colombet M, Soerjomataram I, Parkin DM, Piñeros M, Znaor A, Bray F. Cancer statistics for the year 2020: An overview. International Journal of Cancer. 2021 Apr 5. / [Pub med] Google Scholar

3. Jha AK, Chapagain S, Dhimal M, Subedi R, Kafle U, Thakur C, Khadka K, Budukh A, Dikshit R. Population Based Cancer Registries at Kathmandu, Bhaktapur, Lalitpur, Siraha, Saptari, Dhanusha, Mohattari, West rukum and East Rukum Districts, Nepal-2018. Nepal Health Research Council; 2018. [Google scholar]

4. Rohan Khandelwal. Breast cancer is underdiagnosed in India: Causes, tests, treatment options you should know. October 15, 2020 08:30:56 IST [Web Link]

5. Mohan Giri, Anju Puri,Bibhuti current status of breast cancer in Nepal, International Journal of Research in Medical Sciences June 2019 | Vol 7 | Issue 6 Page 2463 [WebLink][FullText]

6. Nelson HD, Fu R, Cantor A, Pappas M, Daeges M, Humphrey L. Effectiveness of breast cancer screening: systematic review and meta-analysis to update the 2009 US Preventive Services Task Force recommendation. Annals of internal medicine. 2016 Feb 16;164(4):244-55 [Pub med ]

7. Cancer Screening Guidelines | Detecting Cancer Early Jul 30, 2020 the American Cancer Society [Web Link]

8. Al-Mousa DS, Alakhras M, Hossain SZ, AlSa'di AG, Al Hasan M, Al-Hayek Y, Brennan PC. Knowledge, Attitude and Practice Around Breast Cancer and Mammography Screening Among Jordanian Women. Breast Cancer: Targets and Therapy. 2020;12:231.[Google scholar] [Full Text]

9. Rosemary A. Knowledge, Attitude And Practice Towards Breast Cancer Screening Among Female Out-Patients Aged 18- 65 Years Seeking Health Care Services At Jaramogi Oginga Odinga Teaching And Referral Hospital, Kisumu County International Journal of Scientific and
Research Publications, Volume 9, Issue 5, May 2019 [Full Text] [Google Scholar]

10. Tilaki KH, Auladi S. Awareness, attitude, and practice of breast cancer screening women, and the associated sociodemographic characteristics, in northern Iran. Iranian journal of cancer prevention. 2015 Aug;8(4). [Pub med] [Google scholar]

11. Santhana L,Sagundevi G, A cross sectional study on knowledge about breast cancer among women aged 20-30 years Int J Community Med Public Health. 2017 Nov;4(11):4131-4136 [full Text]

12. Kumari S. Awareness of carcinoma breast in women of a selected village population. International Journal of Health and Clinical Research. 2021 Feb 28;4(4):278-80. [Google scholar]

13. Antony MP, Surakutty B, Vasu TA, Chisthi M. Risk factors for breast cancer among Indian women: A case-control study. Nigerian journal of clinical practice. 2018 Apr 6;21(4).C ht [Web Link] [Google scholar] [Full Text] [PubMed]

14. Sathian B, Nagaraja SB, Banerjee I, Sreedharan J, De A, Roy B, Rajesh E, Senthilkumaran S, Hussain SA, Menezes RG. Awareness of breast cancer warning signs and screening methods among female residents of Pokhara valley, Nepal. Asian Pacific journal of cancer prevention. 2014;15(11):4723-6. [Full Text][Pub Med]

15. Marahatta SB, Sharma S. Knowledge and practice of breast self-examination among women of reproductive age in Butwal Sub Metropolitan City. Journal of Manmohan Memorial Institute of Health Sciences. 2018 Sep 22;4(1):117-29. [WebLink] [GoogleScholar][FullText] [DOI]

16. Heena H, Durrani S, Riaz M, AlFayyad I, Tabasim R, Parvez G, Abu-Shaheen A. Knowledge, attitudes, and practices related to breast cancer screening among female health care professionals: a cross sectional study. BMC women's health. 2019 Dec;19(1):1-1.[Full Text] [PubMed]

17. Hussen MS, Belete GT. Knowledge and attitude toward eye donation among adults, Northwest Ethiopia: A community-based, cross-sectional study. Middle East African journal of ophthalmology. $2018 \mathrm{Jul} ; 25$ (34):126.w[Full Text] [Web Link] [Google Scholar] [PubMed]

18. Solikhah S, Promthet S, Hurst C. Awareness level about breast cancer risk factors, 
Ratna Kumari Maharjan et.al. Awareness, attitude and practices regarding breast cancer screening among community women.

barriers, attitude and breast cancer screening among Indonesian women. Asian Pacific journal of cancer prevention: APJCP. 2019;20 (3):877.[Google Scholar]

19. [\{Alshahrani M, Alhammam SY, Al Munyif HA, Alwadei AM, Alwadei AM, Alzamanan SS, Aljohani NS. Knowledge, attitudes, and practices of breast cancer screening methods among female patients in primary healthcare centers in Najran, Saudi Arabia. Journal of Cancer Education. 2019 Dec;34(6):1167-72. [Google Scholar]

20. Dibisa TM, Gelano TF, Negesa L, Hawareya TG, Abate D. Breast cancer screening practice and its associated factors among women in Kersa District, Eastern
Ethiopia. The Pan African medical journal. 2019; 33. [Google Scholar]

21. Sah SK,Pradhan A,Neupane N,Shah S,Shrestha P.Knowledge,Attitude and Practice regarding prevention and screening of breast cancer among reproductive age women, Arch Cancer Research.2019(8):1:1 [Full Text][Google Scholar]

How to cite this article: Maharjan RK, Panthee B, Awale S. Awareness, attitude and practices regarding breast cancer screening among community women. Int J Health Sci Res. 2021; 11(8): 158-166. DOI: https://doi.org/10.52403 /ijhsr.20210823 